\title{
Antimycobacterial and HIV-1 Reverse Transcriptase Activity of Julianaceae and Clusiaceae Plant Species from Mexico
}

\author{
Rocio Gómez-Cansino, ${ }^{1}$ Clara Inés Espitia-Pinzón, ${ }^{2}$ María Guadalupe Campos-Lara, ${ }^{3}$ \\ Silvia Laura Guzmán-Gutiérrez, ${ }^{2,4}$ Erika Segura-Salinas, ${ }^{2}$ Gabriela Echeverría-Valencia, ${ }^{2}$ \\ Laura Torras-Claveria, ${ }^{5}$ Xochitl Marisol Cuevas-Figueroa, ${ }^{6}$ and Ricardo Reyes-Chilpa ${ }^{1}$ \\ ${ }^{1}$ Instituto de Química, Departamento de Productos Naturales, Universidad Nacional Autónoma de México, 04510 México, DF, Mexico \\ ${ }^{2}$ Departamento de Inmunología, Instituto de Investigaciones Biomédicas, Universidad Nacional Autónoma de México, \\ 04510 México, DF, Mexico \\ ${ }^{3}$ Hospital Infantil de México Federico Gómez, Dr. Márquez No. 162, Colonia Doctores, 06720 México, DF, Mexico \\ ${ }^{4}$ Cátedra CONACyT, Mexico \\ ${ }^{5}$ Departamento de Productos Naturales, Biología Vegetal y Edafología, Facultad de Farmacia, Universitat de Barcelona, \\ Avenida Diagonal 643, Barcelona, 08028 Catalonia, Spain \\ ${ }^{6}$ Instituto de Botánica (IBUG), Centro Universitario de Ciencias Biológicas y Agropecuarias, Universidad de Guadalajara, \\ 45221 Zapopan, JAL, Mexico
}

Correspondence should be addressed to Ricardo Reyes-Chilpa; chilpa@unam.mx

Received 18 December 2014; Accepted 31 March 2015

Academic Editor: Veronique Seidel

Copyright ( 2015 Rocio Gómez-Cansino et al. This is an open access article distributed under the Creative Commons Attribution License, which permits unrestricted use, distribution, and reproduction in any medium, provided the original work is properly cited.

\begin{abstract}
The extracts of 14 Julianaceae and 5 Clusiaceae species growing in Mexico were tested in vitro $(50 \mu \mathrm{g} / \mathrm{mL})$ against Mycobacterium tuberculosis $\mathrm{H} 37 \mathrm{Rv}$ and HIV reverse transcriptase (HIV-RT). The Julianaceae bark and leaf extracts inhibited M. tuberculosis $(>84.67 \%)$ and HIV-RT (<49.89\%). The Clusiaceae leaves extracts also inhibited both targets $(>58.3 \%$ and $>67.6 \%)$, respectively. The $\mathrm{IC}_{50}$ values for six selected extracts and their cytotoxicity $(50 \mu \mathrm{g} / \mathrm{mL})$ to human macrophages were then determined. Amphipterygium glaucum, A. molle, and A. simplicifolium fairly inhibited M. tuberculosis with $\mathrm{IC}_{50}$ of $1.87-2.35 \mu \mathrm{g} / \mathrm{mL}$; but their IC . $_{50}$ against HIV-RT was 59.25-97.83 $\mu \mathrm{g} / \mathrm{mL}$. Calophyllum brasiliense, Vismia baccifera, and Vismia mexicana effect on M. tuberculosis was noteworthy ( $\mathrm{IC}_{50} 3.02-3.64 \mu \mathrm{g} / \mathrm{mL}$ ) and also inhibited RT-HIV (IC $5026.24-35.17 \mu \mathrm{g} / \mathrm{mL}$ ). These 6 extracts $(50 \mu \mathrm{g} / \mathrm{mL})$ presented low toxicity to macrophages ( $<23.8 \%)$. The HPLC profiles of A. glaucum, A. molle, and A. simplicifolium indicated that their antimycobacterial activity cannot be related to masticadienonic, $3 \alpha$, or $3 \beta$-hydromasticadienonic acids, suggesting that other compounds may be responsible for the observed activity or this might be a synergy result. The anti-HIV-RT and antimycobacterial activities induced by $C$. brasiliense can be attributed to the content of calanolides A, B, as well as soulatrolide.
\end{abstract}

\section{Introduction}

Tuberculosis (TB) is an illness caused by the slow-growing acid-fast bacillus Mycobacterium tuberculosis. In 1993, TB declared a global emergency by the World Health Organization [1]. In 2013, there were 9 million new cases and 1.5 million deaths; this figure included 0.4 million fatalities associated with HIV patients [2]. Mycobacterium tuberculosis is facultative intracellular bacteria that have developed resistance to first and second line antituberculosis drugs. Antibiotic resistance and multidrug-resistant $\mathrm{TB}$ strains are a serious problem due to the lack of results in treatment design directed to disease control and eradication $[3,4]$. Due to the recent rise of TB associated with the human immunodeficiency virus VIH and the rapid spread of multidrug resistance TB strains, new classes of antimycobacterial compounds are required [5]. Compounds obtained from plants can be an important source of novel leads in the field of antituberculosis therapeutic agents [6-8], as well as against human immunodeficiency virus (HIV) [9]. 
TABLE 1: HIV-1 RT and M. tuberculosis inhibition by Julianaceae and Clusiaceae extracts* and their cytotoxicity to THP-1 human cell line.

\begin{tabular}{|c|c|c|c|c|c|}
\hline Species & Location/voucher & Part used/gender & $\begin{array}{l}\text { \% inhibition } \\
\text { of HIV-1 RT }\end{array}$ & $\begin{array}{l}\% \text { inhibition of } \\
\text { M. tuberculosis }\end{array}$ & $\begin{array}{c}\% \\
\text { cytotoxicity }\end{array}$ \\
\hline \multicolumn{6}{|l|}{ Julianaceae } \\
\hline \multirow{4}{*}{ Amphipterygium amplifolia } & \multirow{2}{*}{ Jalisco/15637 } & Stem bark/M & $24.8 \pm 2.1$ & $90.1 \pm 0.6$ & $14.0 \pm 1.8$ \\
\hline & & Leaf/M & $18.7 \pm 3.2$ & $89.8 \pm 0.1$ & $16.3 \pm 2.3$ \\
\hline & \multirow{2}{*}{ Jalisco/15638 } & Stem bark/F & $36.7 \pm 2.8$ & $89.1 \pm 0.4$ & $23.3 \pm 1.7$ \\
\hline & & Leaf/F & $46.5 \pm 4.8$ & $89.7 \pm 0.2$ & $25.5 \pm 1.9$ \\
\hline \multirow{3}{*}{ Amphipterygium molle } & Jalisco/15639 & Stem bark/M & $19.3 \pm 2.2$ & $89.6 \pm 0.5$ & $19.7 \pm 1.0$ \\
\hline & \multirow{2}{*}{ Jalisco/15640 } & Stem bark/F & $11.3 \pm 0.7$ & $88.7 \pm 0.7$ & $12.5 \pm 1.2$ \\
\hline & & Leaf/F & $49.8 \pm 1.8$ & $89.0 \pm 0.6$ & $19.5 \pm 1.5$ \\
\hline \multirow{2}{*}{ Amphipterygium adstringens } & \multirow{2}{*}{ Jalisco/15641 } & Stem bark/M & $9.2 \pm 2.7$ & $88.2 \pm 0.1$ & $18.4 \pm 1.5$ \\
\hline & & Leaf/M & $6.1 \pm 0.7$ & $90.2 \pm 0.7$ & $25.1 \pm 1.9$ \\
\hline \multirow{3}{*}{ Amphipterygium glaucum } & \multirow{2}{*}{ Michoacán/15644 } & Stem bark/M & $40.0 \pm 2.0$ & $86.9 \pm 0.5$ & $22.9 \pm 1.6$ \\
\hline & & Leaf/M & $48.5 \pm 0.7$ & $89.6 \pm 0.9$ & $10.9 \pm 1.6$ \\
\hline & Michoacán/15645 & Stem bark/F & $21.7 \pm 2.1$ & $84.6 \pm 1.3$ & $19.7 \pm 1.3$ \\
\hline \multirow{2}{*}{ Amphipterygium simplicifolium } & \multirow{2}{*}{ Oaxaca/16125 } & Stem bark/ & $44.3 \pm 1.2$ & $90.3 \pm 0.2$ & $9.2 \pm 1.5$ \\
\hline & & Leaf/ & $7.9 \pm 0.4$ & $90.5 \pm 1.0$ & $19.5 \pm 0.3$ \\
\hline \multicolumn{6}{|l|}{ Clusiaceae } \\
\hline Vismia mexicana & Veracruz/134793 $3^{\S}$ & Leaf & $43.7 \pm 0.7$ & $63.5 \pm 1.1$ & $10.6 \pm 1.4$ \\
\hline Vismia baccifera & Oaxaca/134792 & Leaf & $54.0 \pm 0.8$ & $70.3 \pm 0.5$ & $10.7 \pm 1.7$ \\
\hline Clusia guatemalensis & Oaxaca/134795 & Leaf & $30.5 \pm 2.4$ & $62.1 \pm 0.7$ & $17.1 \pm 1.3$ \\
\hline Clusia lundellii & Oaxaca/136723 & Leaf & $27.3 \pm 1.1$ & $58.3 \pm 0.4$ & $18.3 \pm 1.4$ \\
\hline Calophyllum brasiliense & Veracruz/15526 & Leaf & $67.6 \pm 1.2$ & $82.8 \pm 0.4$ & $23.8 \pm 1.1$ \\
\hline
\end{tabular}

${ }^{*} \mathrm{CH}_{2} \mathrm{Cl}_{2}-\mathrm{MeOH}$ extracts tested at $50 \mu \mathrm{g} / \mathrm{mL} . \mathrm{M}=$ male, $\mathrm{F}=$ female. Vouchers at IMSSM or FCME

Preliminary data indicate that Amphipterygium adstringens (Julianaceae) is a promising source of anti-TB compounds, since the stem bark extract inhibited in 95\% the growth of $M$. tuberculosis at $50 \mu \mathrm{g} / \mathrm{mL}$; this tree species is used in Mexican Traditional Medicine for the treatment of tuberculosis and other respiratory diseases [10]. However, other 4 species of this genus found in Mexico have not been investigated yet against $M$. tuberculosis or HIV. Julianaceae species are dioecious; that is, male and female trees are found; some morphological features are useful for sex differentiation; for instance, female specimens show flowers ordinarily in groups of four in a receptacle [11]. So far, the influence of sex in the production of secondary metabolites has been poorly documented; however, in the case of $A$. adstringens bark, an accumulation of masticadienonic and $3 \alpha$-hydroxymasticadienonic acids has been found to be higher in female plants [12].

The leaf extracts of the 23 species of Clusiaceae distributed in Mexico have been examined against HIV-1 RT [9], but not against $M$. tuberculosis. Among the 5 most active species against HIV-1 RT, the tropical tree Calophyllum brasiliense is remarkable [9]: its leaves contain dipiranotetracyclic coumarins, such as calanolides A, B, and C, as well as inophyllums, mainly soulatrolide. Such compounds have been found to be active against HIV-1 RT [13] and M. tuberculosis [14]. The calanolide A shows potent and specific inhibition of HIV-RT [15]; this compound has been synthesized and is currently in pharmacological research phases II/III [16]. The hexane leaf extract of C. brasiliense has also been proposed for developing a standardized phytodrug; however, to achieve this goal, there is a need to obtain biological material with a high content of active compounds $[9,17]$. The active compounds for other Clusiaceae species are still unknown.

The aim of this study was to evaluate Mexican Julianaceae and Clusiaceae crude plant extracts against Mycobacterium tuberculosis H37Rv and HIV-RT. Plants were selected according to two criteria: Julianaceae species, based on their use to treat tuberculosis in Mexican Traditional Medicine [18], whereas Clusiaceae species, based on bioprospective and chemotaxonomical data.

\section{Methods}

2.1. Plant Material. Clusiaceae and Julianaceae species were collected from different localities in Mexico (Table 1). Voucher specimens were deposited at the Herbarium Facultad de Ciencias (FCME) of the Universidad Nacional Autónoma de México and the Medicinal Herbarium (IMSSM) of Instituto Mexicano del Seguro Social.

2.2. Preparation of Extracts. The leaves of Clusiaceae species were used for preparing the tested extracts, whereas, in the case of Julianaceae, the extracts were prepared from the bark 
<smiles>CC1(C)CC[C@]2(C(=O)O)CC[C@]3(C)C(=CCC4[C@@]5(C)CC[C@@H](O)C(C)(C)C5CC[C@]43C)C2C1</smiles><smiles>C/C(=C\CC[C@H](C)[C@H]1CC[C@]2(C)C3CCC4C(C)(C)C(=O)CC[C@]4(C)C3CC[C@]12C)C(=O)O</smiles><smiles>C/C(=C/CC[C@H](C)[C@H]1CC[C@]2(C)C3=CCC4C(C)(C)CC[C@H](O)[C@@]4(C)CC3CC[C@]12C)C(=O)O</smiles><smiles>C/C(=C/CC[C@H](C)[C@H]1CC[C@]2(C)C3=CCC4C(C)(C)[C@@H](O)CC[C@]4(C)C3CC[C@]12C)C(=O)O</smiles><smiles>CCCC(CCC(=O)O)c1c2c(c(O)c3c1O[C@H](C)[C@@H](C)C3=O)C=CC(C)(C)O2</smiles><smiles>CCCc1cc(=O)oc2c3c(c4c(c12)OC(C)(C)C=C4)O[C@H](C)[C@H](C)[C@H]3O</smiles>

6<smiles>C[C@H]1Oc2c3c(c4c(-c5ccccc5)cc(=O)oc4c2O1)[C@@H](O)[C@H](C)[C@@H](C)O3</smiles>

7

FIgURE 1: Triterpenes from Julianaceae species: oleanolic acid 1, masticadienonic acid 2, $3 \alpha$-hydroxymasticadienonic acid 3, and $3 \beta$ hydroxymasticadienonic acid 4. Compounds from C. brasiliense: apetalic acid 5, calanolide B 6, and soulatrolide 7.

and leaves of specimens of different genders (male or female). All plant materials $(100 \mathrm{~g})$ were dried at room temperature under darkness, ground, and macerated three times for $24 \mathrm{~h}$ with a mixture of $\mathrm{CH}_{2} \mathrm{Cl}_{2}-\mathrm{MeOH}(1: 1,150 \mathrm{~mL})$. The extracts were concentrated in vacuo to dryness and stored at room temperature until use.

2.3. Stock and Working Plant Extract Solution. Stock solutions of all extracts were prepared in 100\% dimethyl sulfoxide (DMSO) at a concentration of $2000 \mu \mathrm{g} / \mathrm{mL}$ and sterilized by filtration throughout a $0.22 \mu \mathrm{m}$ PTFE membrane. For M. tuberculosis susceptibility tests, extract solutions were prepared by diluting the stock extract in sterile $7 \mathrm{H} 9$ broth to obtain a $100 \mu \mathrm{g} / \mathrm{mL}$ concentration, whereas extract solutions for anti-RT tests were diluted in the buffer provided by the kit manufacturer to obtain a working concentration of $200 \mu \mathrm{g} / \mathrm{mL}$ (Lenti RT, Cavidi Tech).

2.4. Cell Culture. To assess cytotoxicity, human monocytic leukemia THP-1 cells from ATCC were cultured in RPMI
1640 medium supplemented with nonheat-inactivated $20 \%$ fetal bovine serum, $1 \mathrm{mM}$ HEPES. For all experiments, THP1 were cultured in $75 \mathrm{~cm}^{2}$ Falcon culture flasks under standard culture conditions of $5 \% \mathrm{CO}_{2}$ at $37^{\circ} \mathrm{C}$ at an initial density of $1.0 \times 10^{6}$ cells $/ \mathrm{mL}$. The cultures were maintained by adding fresh medium with $10 \%$ fetal bovine serum every 2-3 days.

2.5. HPLC Analysis of Extracts of Julianaceae and C. brasiliense. The bark extracts of Julianaceae and $C$. brasiliense leaves were analyzed by HPLC (Agilent 1100 series) according to previous reports $[17,19]$. In the case of Julianaceae, the compounds oleanolic acid $\mathbf{1}$, masticadienonic acid 2, $3 \alpha$-hydroxymasticadienonic acid 3 , and $3 \beta$ hydroxymasticadienonic acid 4 were quantified, whereas, for C. brasiliense, the concentrations of apetalic acid 5, calanolide B 6, and soulatrolide 7 were determined (Figure 1). The chromatographic column Kromasil $100 \mathrm{C18}$, $5 \mu \mathrm{m}, 150 \times 4.6 \mathrm{~mm}$ was used to analyze Julianaceae species; the mobile phase was a mixture of $0.1 \%$ aqueous acetic acid, acetonitrile containing $0.1 \%$ acetic acid and grade reagent 
alcohol (90\% ethanol $+5 \%$ methanol $+5 \%$ 2-propanol) in a proportion $18: 52: 30 \mathrm{v} / \mathrm{v}$ for $25 \mathrm{~min}$ with an isocratic flowrate of $1.0 \mathrm{~mL} / \mathrm{min}$; the injection volume was $10 \mu \mathrm{L}$, and the elute was analyzed at $215 \mathrm{~nm}$. Each analysis was followed by a $5 \mathrm{~min}$ washing with $100 \%$ acetonitrile and an equilibration period with the mobile phase for $15 \mathrm{~min}$.

The components of $C$. brasiliense extract were quantified using the chromatographic column Kromasil $100 \mathrm{C} 18,5 \mu \mathrm{m}$, $250 \times 4.6 \mathrm{~mm}$. The isocratic system acetonitrile water $(6: 4$ $\mathrm{v} / \mathrm{v}$ ) with the flowrate of $1 \mathrm{~mL} / \mathrm{min}$ was used for $40 \mathrm{~min}$; the injection volume was $10 \mu \mathrm{L}$ and the detection wavelength $284 \mathrm{~nm}$. Each analysis was followed by a $5 \mathrm{~min}$ washing with $100 \%$ acetonitrile, 2 min with water, and an equilibration period with the mobile phase for $3 \mathrm{~min}$.

Identification of the compounds in the extracts was carried out by comparison with the retention times (RT) of pure compounds. The calibration graphs of standards were calculated and each compound was injected by triplicate over two different days; Julianaceae compounds were injected in seven different concentrations $(20,40,60,100,140,200$, and $500 \mu \mathrm{g} / \mathrm{mL}$ ) whereas standards from C. brasilense, in six different concentrations $(20,50,80,120,150$, and $200 \mu \mathrm{g} / \mathrm{mL})$. The linear regressions and their coefficients of determination $\left(R^{2}\right)$ were calculated for each compound as follows: oleanolic acid 1, $y=3.7085 x-17.043,0.9987$; masticadienonic acid 2, $y=10.766 x+4.3811,0.9990$; mixture of $3 \alpha$ and $\beta$-hydroxymasticadienonic acids (3 \& 4), $y=11.466 x+$ 22.14, 0.9993; apetalic acid 5, $y=19.547 x+135.64,0.9933$; calanolide B 6, $y=27.786 x+13.369,0.9995$ and soulatrolide $7, y=35.075 x+209.85,0.9934$. Finally, the percentage of each compound in the extracts was calculated interpolating the linear regression equation. The results are reported as the percentage of extract (Table 3).

2.6. HIV-1 RT Inhibition Test. The extracts were evaluated by a nonradioactive immunocolorimetric assay (Lenty RT Activity Assay, Cavidi Tech) according to the protocol provided by the manufacturer. All extracts were first tested at $50 \mu \mathrm{g} / \mathrm{mL}$ with a final DMSO concentration of $0.5 \% \mathrm{v} / \mathrm{v}$. Reported values are means of 5 replicates \pm SEM. The $\mathrm{IC}_{50}$ values were calculated only for extracts that inhibited $\geq 50 \%$ the enzymatic activity. These extracts were tested at 7 concentrations 3.125 to $200 \mu \mathrm{g} / \mathrm{mL}$ with increments of 0.3 logarithms. Reported values are means of 3 replicates \pm SEM. Nevirapine, a nonnucleoside reverse transcriptase inhibitor (NNRTI), was used as a positive control from $0.01 \mu \mathrm{M}$ to $1 \mathrm{mM}$ with increments of 1 logarithm.

2.7. Antimycobacterial Screening by Microplate Alamar Blue. The activity of all extracts was tested using the microplate Alamar blue assay as previously described [20, 21]. Outer wells were filled with sterile distilled water $(200 \mu \mathrm{L})$ to prevent dehydration in experimental wells. Colum 2 (B to $\mathrm{G}$ wells) was used to evaluate the reference drug rifampin; serial twofold dilutions in $100 \mu \mathrm{L}$ of Middlebrook $7 \mathrm{H} 9$ medium were performed to obtain concentrations from 2.0 to $0.06 \mu \mathrm{g} / \mathrm{mL}$. Wells $10 \mathrm{E}$ and F were used for DMSO control, and wells $11 \mathrm{~B}$ to $11 \mathrm{E}$ for the drug free control. One-hundred $\mu \mathrm{L}$ of supplemented $7 \mathrm{H} 9$ broth plus $100 \mu \mathrm{L}$ the bacterial inoculum $\left(1 \times 10^{6} \mathrm{ufc} / \mathrm{mL}\right)$ was added to each of these wells. Simultaneously a diluted control 1:100 was prepared from the bacterial suspension, representing $1 \%$ growth of the bacterial population tested. All other wells received $100 \mu \mathrm{L}$ of the extract solution $(100 \mu \mathrm{g} / \mathrm{mL})$ and $100 \mu \mathrm{L}$ bacterial inoculums. The final concentration of DMSO in well was $<1.0 \% \mathrm{v} / \mathrm{v}$, and all extracts were tested at $50 \mu \mathrm{g} / \mathrm{mL}$. The $\mathrm{IC}_{50}$ values were calculated only for those extracts that inhibited $\geq 50 \%$ the mycobacterial growth; these extracts were tested at seven concentrations ( 3.125 to $200 \mu \mathrm{g} / \mathrm{mL}$ ) with increments of 0.3 logarithms. Each microplate was incubated for 710 days at $37^{\circ} \mathrm{C}$; after incubation, one growth control was developed with a mixture of $20 \mu \mathrm{L}$ of Alamar blue solution (ABD Serotec) and $5 \mu \mathrm{L}$ of sterile $20 \%$ Tween 80 . The plates were reincubated at $37^{\circ} \mathrm{C}$ for $24 \mathrm{~h}$. After this period, if the control well turned from blue (no growth) to pink (growth), the remaining wells were treated with AlamarTween, as previously described, and incubated for additional $24 \mathrm{~h}$. Reduction of Alamar blue was calculated according to the manufacturer protocol. Optical density of the plate was measured at 540 and $600 \mathrm{~nm}$ with a spectrophotometer. The percentage of inhibition of the crude extracts was defined as 100 - percentage of reduction of Alamar blue.

2.8. Cytotoxicity Assay. Crude extracts were evaluated against human macrophages THP1 cell line. The differentiation of THP1 cells was performed with PMA (phorbol 12-myristate 13 acetate) $50 \mathrm{nM}$ [22]. Twenty thousand cells in the differentiation process were placed in each well, and the plates were incubated for $72 \mathrm{~h}$ at $37^{\circ} \mathrm{C}$, and $5 \% \mathrm{CO}_{2}$ atmosphere. After the incubation, the plates were washed twice with RPMI supplemented medium and $100 \mu \mathrm{L}$ of the extract solutions $(50 \mu \mathrm{g} / \mathrm{mL})$ was added to each well and reincubated for $24 \mathrm{~h}$. After the reincubation time $10 \mu \mathrm{L}$ of Alamar blue solution was added to each well, and the plates were reincubated for $24 \mathrm{~h}$. The anthracycline doxorubicin was used as a positive control, and the data were interpreted as indicated by the manufacturer. Cytotoxicity was calculated as the ratio of the average OD (570 and $600 \mathrm{~nm}$ ) obtained as compared with control wells (untreated macrophages).

\section{Results}

3.1. Screening of Plant Extracts. The 14 Julianaceae extracts displayed high antimycobacterial activity (>84\%). These results are consistent with previously published data for $A$. adstringens, which inhibited $95 \%$ of mycobacterial activity at the same concentration [10]. Regarding the 5 Clusiaceae extracts, only C. brasiliense showed similar potency (82\%) as compared with Julianaceae; the other Clusiaceae species inhibited the growth of $M$. tuberculosis $\mathrm{H} 37 \mathrm{Rv}$ in the range of 58.3 to $70.3 \%$. Concerning HIV-RT, the Clusiaceae extracts showed inhibition in a range of 27.3 to $67.6 \%$, whereas the Julianaceae extracts inhibited this enzyme in the range of 7.9 to $49.8 \%$ (Table 1 ). Since macrophages are potential targets of M. tuberculosis and HIV, in order to assess the cytotoxicity of the extracts, they were tested against macrophages derived 
TABLE 2: $\mathrm{IC}_{50}$ of Clusiaceae and Julianaceae extracts.

\begin{tabular}{lcc}
\hline \multirow{2}{*}{ Species } & \multicolumn{2}{c}{ IC50 \pm SEM $(\mu \mathrm{g} / \mathrm{mL})$} \\
\hline A. glaucum/M & M. tuberculosis $\mathrm{H} 37 \mathrm{rV}$ & VIH-1 RT \\
A. molle/M & $2.87 \pm 1.75$ & $97.83 \pm 2.03$ \\
A. simplicifolium & $2.35 \pm 0.97$ & $89.59 \pm 1.97$ \\
C. brasiliense & $3.02 \pm 1.06$ & $59.21 \pm 1.23$ \\
V. baccifera & $3.82 \pm 1.19$ & $26.24 \pm 1.92$ \\
V. mexicana & $3.64 \pm 1.35$ & $31.75 \pm 1.34$ \\
\hline
\end{tabular}

TABLE 3: Chemical composition (\%) of Julianaceae bark extracts.

\begin{tabular}{lccc}
\hline Extracts & \multicolumn{3}{c}{ Compounds \% } \\
& $\mathbf{1}^{*}$ & $\mathbf{2}^{* *}$ & $\mathbf{3}$ \& 4 \\
\hline A. amplifolia/M & $\mathrm{n} / \mathrm{d}$ & 8.71 & 8.77 \\
A. amplifolia/F & $\mathrm{n} / \mathrm{d}$ & 4.17 & 4.42 \\
A. molle/M & $\mathrm{n} / \mathrm{d}$ & 4.73 & 8.53 \\
A. molle/F & $\mathrm{n} / \mathrm{d}$ & 3.46 & 3.35 \\
A. glaucum/M & $\mathrm{n} / \mathrm{d}$ & 0.15 & 3.63 \\
A. glaucum/F & $\mathrm{n} / \mathrm{d}$ & $\mathrm{n} / \mathrm{d}$ & $\mathrm{n} / \mathrm{d}$ \\
A. adstringens/M & $\mathrm{n} / \mathrm{d}$ & 14.23 & 10.91 \\
A. simplicifolium & $\mathrm{n} / \mathrm{d}$ & 4.15 & 3.35 \\
\hline
\end{tabular}

${ }^{*}(\mathrm{RT}=8.06 \mathrm{~min}),{ }^{* *}(\mathrm{RT}=17.29 \mathrm{~min}), \mathrm{n} / \mathrm{d}:$ not detected.

from THP1 cells. The extracts inhibited in $9.2-25.5 \%$ of the growth of macrophages when tested at $50 \mu \mathrm{g} / \mathrm{mL}$, suggesting they are innocuous at the tested concentrations (Table 1).

The $\mathrm{IC}_{50}$ values were calculated for six species selected for their high activity in both targets. Three of them were Julianaceae (stem bark) and three Clusiaceae (leaves) (Table 2). The six extracts showed potent antimycobacterial activity with $\mathrm{IC}_{50}$ in the range 1.8 to $3.8 \mu \mathrm{g} / \mathrm{mL}$; however, these extracts were less potent inhibiting HIV-RT, since they ranged from 26.2 (C. brasiliense) to $97.8 \mu \mathrm{g} / \mathrm{mL}$ (A. glaucum). Regarding HIV-RT inhibitory properties of plant extracts, several authors have pointed out that an $\mathrm{IC}_{50} \leq 50 \mu \mathrm{g} / \mathrm{mL}$ may be considered potent $[23,24]$; however, a similar parameter has not been proposed for M. tuberculosis. Assuming the same parameter, the extracts from C. brasiliense, V. baccifera, and $V$. mexicana displayed similar potency to both targets, while the extracts from A. glaucum, A. molle, and A. simplicifolium were potent only to M. tuberculosis (Table 2).

3.2. HPLC Analysis of Extracts of Julianaceae and C. brasiliense. The HPLC analysis of the three selected Julianaceae bark extracts showed the following metabolites: masticadienonic acid 2 and $\alpha$ - and/or $\beta$-hydroxymasticadienonic acids ( 3 and 4 ). Under the chromatographic conditions used, quantifying individually the isomers 3 and 4 was not possible due to their similar retention times ( $\mathrm{Rt}=20.7$ and $20.9 \mathrm{~min}$, resp.); therefore, these compounds were quantified as the mixture of acids. Oleanolic acid $\mathbf{1}$, which has been previously reported as a constituent of $A$. adstringens bark, was not detected in the extracts studied (Table 3 ). The concentration of compounds $\mathbf{2}$ and mixture of $\mathbf{3}$ and $\mathbf{4}$ may not be related to M. tuberculosis activity since these three compounds from the most active extracts $\left(\mathrm{IC}_{50}<2.35 \mu \mathrm{g} / \mathrm{mL}\right.$ ) were found in high (A. amplifolia, male), medium (A. simplicifolium), and low (A. glaucum, male) content. In addition, the other Julianaceae bark extracts which also showed significant antimycobacterial activity ( $>84.6 \%$ at $50 \mu \mathrm{g} / \mathrm{mL}$ ) showed no correlation with the concentrations of the analyzed compounds, as they include the species with the highest concentrations of 2, 3 , and 4 (A. adstringens from male trees; $14.23 \%$ and $10.91 \%$, resp.), but also the species devoid of these compounds (A. glaucum female). The above findings suggest that the antimycobacterial active principle in the Julianaceae extracts is not compound $\mathbf{2}, \mathbf{3}$, or $\mathbf{4}$. The same can be stated for HIVRT, since almost all of these extracts, with the exception of $A$. simplicifolium, showed poor activity (Tables 1 and 2).

With regard to gender and production of secondary metabolites, male specimens showed the higher levels of masticadienonic acid $\mathbf{2}$ and $3 \alpha$-hydroxymasticadienonic $\mathbf{3}$, as compared to extracts from female specimens (Figure 2). Our results are opposite to those previously published, in which the accumulation of compounds 2 and 3 was higher in female plants [12].

In the case of Clusiaceae species, only C. brasiliense was analyzed by HPLC (Figure 3$)$. Apetalic acid $(\mathrm{Rt}=18.64)$, calanolide B (Rt $=23.34)$, and soulatrolide $(\mathrm{Rt}=25.30)$ were present in $0.01 \%, 2.4 \%$, and $6.8 \%$, respectively. Previously, a high antimycobacterial and anti-HIV-RT activity of soulatrolide and calanolide B has been reported [14]. Hence, they can be considered, respectively, as the antimycobacterial and anti-HIV active principles.

\section{Discussion}

HIV infection decreases the number of CD4+ lymphocytes, so it is quite probable that an HIV+ patient can acquire or reactivate tuberculosis disease [25]. During the last 30 years, 24 anti-HIV drugs have been approved by the FDA [9] but any novel anti-TB drug. The rapid spread of multidrug resistance to TB strains remarks that new classes of antimycobacterial compounds are now required $[26,27]$. The treatment of patients coinfected with $\mathrm{TB} / \mathrm{HIV}$ presents also additional challenges, such as intolerance and contraindications for the use of combined drugs and low attachment to medication regime due to the administration of a large number of medications. The highly active retroviral therapy (HAART) for HIV patients involves the administration of a protease inhibitor and two reverse transcriptase inhibitors (1 nonnucleoside +1 nucleoside type), which represent administration of 20 pills/daily; in addition, monotherapy for TB adds 10 to 12 pills [28]. Moreover, HIV-1 protease inhibitors nullify the effect of the rifampin used as first-line drug for the treatment of TB $[26,27]$. In this context, new drugs are needed, if at all possible, active to both targets.

A previous report indicated that one Amphipterygium species had a promising activity against TB [10], and our results confirm this finding and extend it to the five species of this genus present in Mexico, which are quite potent against M. tuberculosis; however, these extracts showed moderate or poor activity to HIV-RT. No correlation with the content of triterpenoids as masticadienonic acid, $3 \alpha$, 


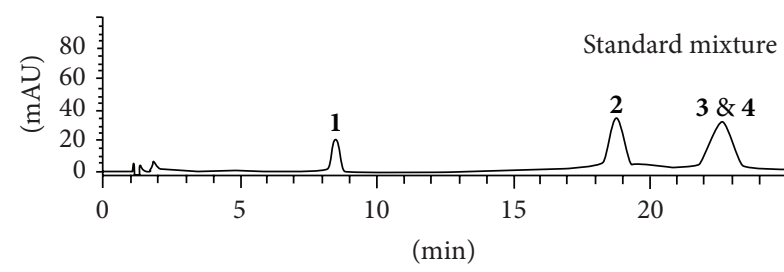

(a)

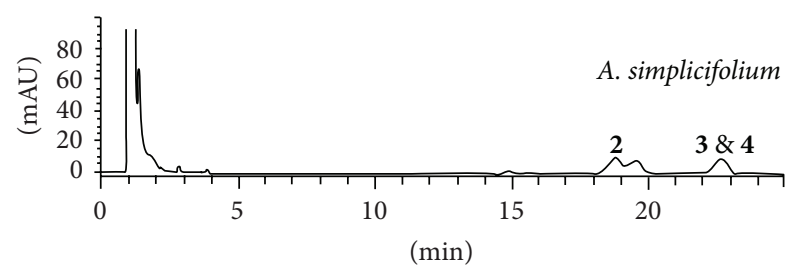

(c)

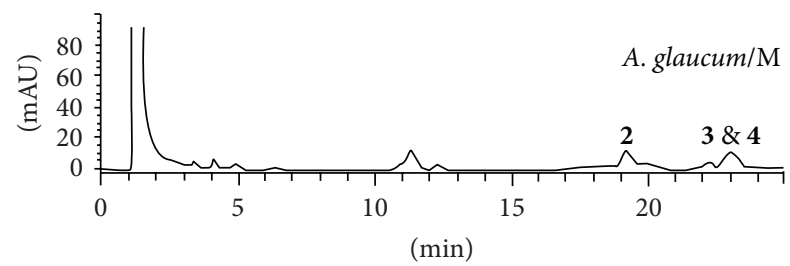

(e)

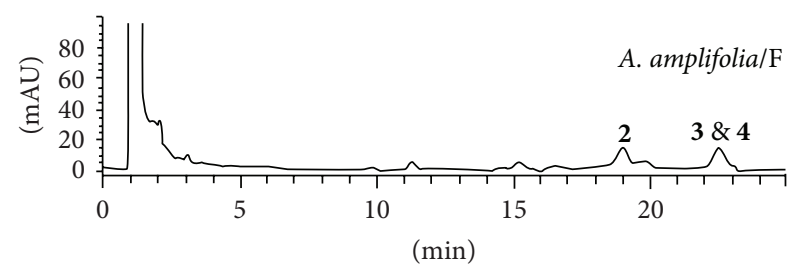

(g)

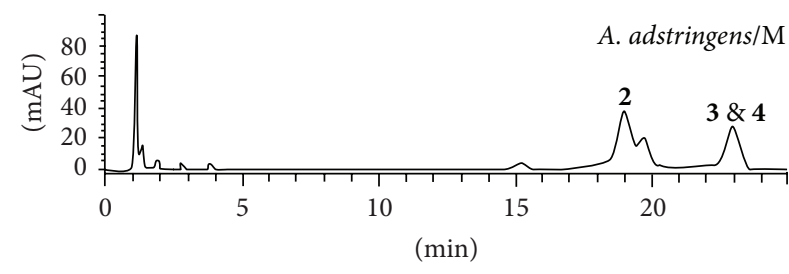

(b)

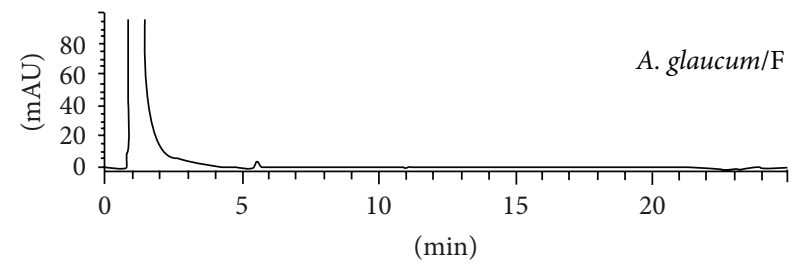

(d)

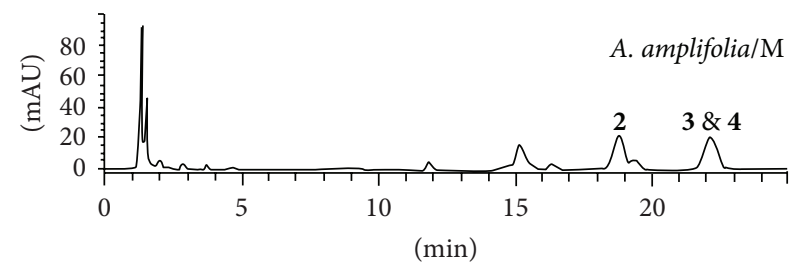

(f)

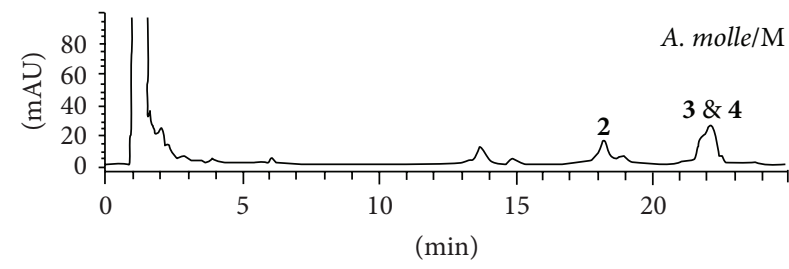

(h)

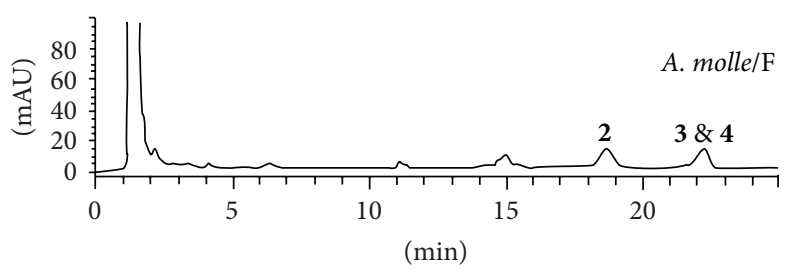

(i)

FiguRE 2: Chromatograms of Julianaceae species extracts and their main triterpenes: oleanolic acid 1, masticadienonic acid 2 , $3 \alpha-$ hydroxymasticadienonic acid $\mathbf{3}$, and $3 \beta$-hydroxymasticadienonic acid 4.

and $3 \beta$-hydromasticadienonic acids was detected for antiTB or anti-RT activities for the extracts of these species and deserves future investigations in order to identify the active compounds. According to our results Amphipterygium species are a source of potent anti-TB extracts with low cytotoxicity to macrophages.

A previous report indicated that the five Clusiaceae species here examined have moderate to high activity against HIV-RT [9], and our results confirm this finding but also show for the first time that they are quite potent to $M$. tuberculosis. In particular, C. brasiliense organic extract from the leaves could be suitable for developing a phytodrug due to its content of active molecules to both targets and the calanolides $\mathrm{A}, \mathrm{B}, \mathrm{C}$, and soulatrolide. Our results also evidence that biodiversity is a useful and valuable source for molecular leads aimed to M. tuberculosis and HIV. To date it has been described at least 84 natural compounds active against $M$. tuberculosis [7]. On the other hand, 120 substances, mainly extracted from plants, have been identified with activity in vitro against HIV [13]. Only a few of them have been examined for both properties.

\section{Conclusion}

In this study, the high antimycobacterial and moderate antiHIV-RT activities of Julianaceae bark extracts, especially 


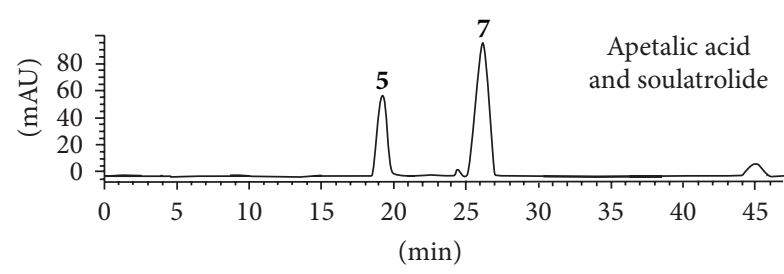

(a)

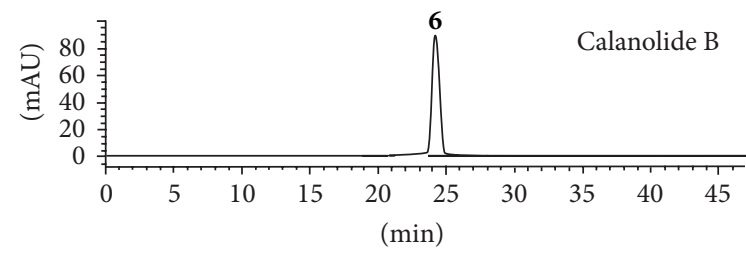

(b)

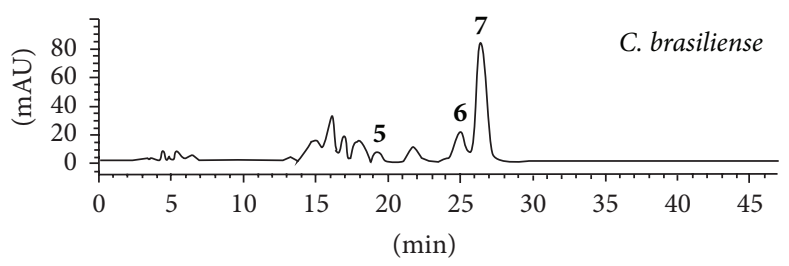

(c)

FIGURE 3: Chromatogram of C. brasiliense extract and its compounds: apetalic acid 5, calanolide B 6, and soulatrolide 7.

Amphipterygium simplicifolium, A. glaucum, and A. molle have been showed. These activities are not related to the triterpenes quantified in this study and suggest that other compounds are the active molecules. Our results provide sustenance to the use of species of Julianaceae plants in Mexican Traditional Medicine in the treatment of tuberculosis. Concerning Clusiaceae, the leaf extracts of the 5 species tested showed good activity against both targets. All the extracts showed low toxicity to human macrophages. Calophyllum brasiliense extract may be suitable for developing a phytodrug with dual activity against HIV-1 and M. tuberculosis due to its content of the active molecules calanolides and soulatrolide.

\section{Conflict of Interests}

The authors declare that there is no conflict of interests regarding the publication of this paper.

\section{Acknowledgments}

This research was supported by Grants PAPIIT-DGAPAUNAM (IG 200513) and NAUTEI of IIB-UNAM. Rocio Gómez Cansino is grateful to Doctorado en Ciencias Biomédicas-UNAM and CONACyT (249620) for providing a scholarship. The authors are grateful to Lucio Lozada and Abigail Aguilar for identification of some botanical specimens, to Dr. Jaume Bastida Armengol for the facilities for a research stay in the Laboratory of Natural Products, School of Pharmacy, University of Barcelona, Spain, and to Dr. Cesar García Zebadúa, Dr. Ignacio González Sánchez, and biologist Griselda Hernández Pasteur for technical assistance.

\section{References}

[1] World Health Organization, "Fact sheets on Tuberculosis," http://www.who.int/mediacentre/factsheets/fs104/en/index .html.

[2] World Health Organization, Global Tuberculosis Report, World Health Organization, Geneva, Switzerland, 2014, http://apps .who.int/iris/bitstream/10665/137094/1/9789241564809_eng.pdf.
[3] I. M. Gould, "Antibiotic resistance: the perfect storm," International Journal of Antimicrobial Agents, vol. 34, supplement 3, pp. S2-S5, 2009.

[4] S. B. Levy and B. Marshall, "Antibacterial resistance worldwide: causes, challenges and responses," Nature Medicine, vol. 10, no. 12, supplement, pp. S122-S129, 2004.

[5] J. Luna-Herrera, M. C. Costa, H. G. González, A. I. Rodrigues, and P. C. Castilho, "Synergistic antimycobacterial activities of sesquiterpene lactones from Laurus spp.", Journal of Antimicrobial Chemotherapy, vol. 59, no. 3, pp. 548-552, 2007.

[6] C. L. Cantrell, S. G. Franzblau, and N. H. Fischer, "Antimycobacterial plant terpenoids," Planta Medica, vol. 67, no. 8, pp. 685694, 2001.

[7] B. R. Copp and A. N. Pearce, "Natural product growth inhibitors of Mycobacterium tuberculosis," Natural Product Reports, vol. 24, no. 2, pp. 278-297, 2007.

[8] M.-T. Gutierrez-Lugo and C. A. Bewley, "Natural products, small molecules, and genetics in tuberculosis drug development," Journal of Medicinal Chemistry, vol. 51, no. 9, pp. 26062612,2008

[9] M. Huerta-Reyes, M. D. C. Basualdo, L. Lozada, M. JimenezEstrada, C. Soler, and R. Reyes-Chilpa, "HIV-1 inhibition by extracts of clusiaceae species from Mexico," Biological and Pharmaceutical Bulletin, vol. 27, no. 6, pp. 916-920, 2004.

[10] I. Rivero-Cruz, L. Acevedo, J. A. Guerrero et al., "Antimycobacterial agents from selected Mexican medicinal plants," Journal of Pharmacy and Pharmacology, vol. 57, no. 9, pp. 1117-1126, 2005.

[11] X. M. Cuevas Figueroa, "A revision of the genus Amphipterygium (Julianaceae)," in Ibugana, pp. 27-47, Uiversidad de Guadalajara, Guadalajara, México, 2005.

[12] A. G. Olivera Ortega, M. Soto Hernández, M. Martinez Vázquez, T. Terrazas Salgado, and F. Solares Arenas, "Phytochemical study of cuachalalate (Amphiptherygium adstringens, Schiede ex Schlecht)," Journal of Ethnopharmacology, vol. 68, no. 1-3, pp. 109-113, 1999.

[13] M. Huerta-Reyes, M. D. C. Basualdo, F. Abe, M. JimenezEstrada, C. Soler, and R. Reyes-Chilpa, "HIV-1 inhibitory compounds from Calophyllum brasiliense leaves," Biological and Pharmaceutical Bulletin, vol. 27, no. 9, pp. 1471-1475, 2004. 
[14] Z.-Q. Xu, W. W. Barrow, W. J. Suling et al., "Anti-HIV natural product $(+)$-calanolide $\mathrm{A}$ is active against both drugsusceptible and drug-resistant strains of Mycobacterium tuberculosis," Bioorganic \& Medicinal Chemistry, vol. 12, no. 5, pp. 1199-1207, 2004.

[15] Y. Kashman, K. R. Gustafson, R. W. Fuller et al., "The calanolides, a novel HIV-inhibitory class of coumarin derivatives from the tropical rainforest tree, Calophyllum lanigerum," Journal of Medicinal Chemistry, vol. 35, no. 15, pp. 2735-2743, 1992.

[16] M. S. Butler, "Natural products to drugs: natural productderived compounds in clinical trials," Natural Product Reports, vol. 25, no. 3, pp. 475-516, 2008.

[17] J. C. García-Zebadúa, G. A. Magos-Guerrero, M. MumbrúMassip et al., "Inhibition of HIV-1 reverse transcriptase, toxicological and chemical profile of Calophyllum brasiliense extracts from Chiapas, Mexico," Fitoterapia, vol. 82, no. 7, pp. 1027-1034, 2011.

[18] INI, Atlas de las Plantas de la Medicina Tradicional Mexicana, Instituto Nacional Indigenista, Mexico City, México, 1st edition, 1994.

[19] A. Navarrete, B. Avula, V. C. Joshi, X. Ji, P. Hersh, and I. A. Khan, "Quantitative determination of triterpenes from Amphiptherygium adstringens by liquid chromatography and thin-layer chromatography and morphological analysis of cuachalalate preparations," Journal of AOAC International, vol. 89, no. 1, pp. $1-7,2006$.

[20] L. A. Collins and S. G. Franzblau, "Microplate Alamar blue assay versus BACTEC 460 system for high- throughput screening of compounds against Mycobacterium tuberculosis and Mycobacterium avium," Antimicrobial Agents and Chemotherapy, vol. 41, no. 5, pp. 1004-1009, 1997.

[21] A. Jimenez-Arellanes, M. Meckes, R. Ramirez, J. Torres, and J. Luna-Herrera, "Activity against multidrug-resistant Mycobacterium tuberculosis in Mexican plants used to treat respiratory diseases," Phytotherapy Research, vol. 17, no. 8, pp. 903-908, 2003.

[22] D. M. Kelly, A. M. C. Ten Bokum, S. M. O’Leary, M. P. O'Sullivan, and J. Keane, "Bystander macrophage apoptosis after Mycobacterium tuberculosis H37Ra infection," Infection and Immunity, vol. 76, no. 1, pp. 351-360, 2008.

[23] B. S. Min, Y. H. Kim, M. Tomiyama et al., "Inhibitory effects of Korean plants on HIV-1 activities," Phytotherapy Research, vol. 15, no. 6, pp. 481-486, 2001.

[24] G. T. Tan, J. M. Pezzuto, A. D. Kinghorn, and S. H. Hughes, "Evaluation of natural products as inhibitors of human immunodeficiency virus type 1 (HIV-1) reverse transcriptase," Journal of Natural Products, vol. 54, no. 1, pp. 143-154, 1991.

[25] J. L. Flynn and J. Chan, "Immunology of tuberculosis," Annual Review of Immunology, vol. 19, pp. 93-129, 2001.

[26] C. R. Driver, S. S. Munsiff, J. Li, N. Kundamal, and S. S. Osahan, "Relapse in persons treated for drug-susceptible tuberculosis in a population with high coinfection with human immunodeficiency virus in New York City," Clinical Infectious Diseases, vol. 33, no. 10, pp. 1762-1769, 2001.

[27] S. Schwander, S. Rusch-Gerdes, A. Mateega et al., "A pilot study of antituberculosis combinations comparing rifabutin with rifampicin in the treatment of HIV-1 associated tuberculosis. A single-blind randomized evaluation in Ugandan patients with HIV-1 infection and pulmonary tuberculosis," Tubercle and Lung Disease, vol. 76, no. 3, pp. 210-218, 1995.
[28] A. L. Pozniak, R. Miller, and L. P. Ormerod, "The treatment of tuberculosis in HIV-infected persons," AIDS, vol. 13, no. 4, pp. 435-445, 1999. 


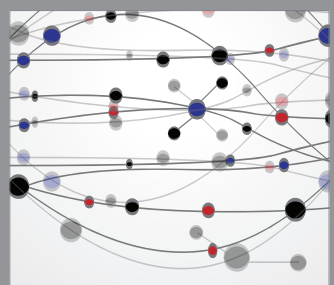

The Scientific World Journal
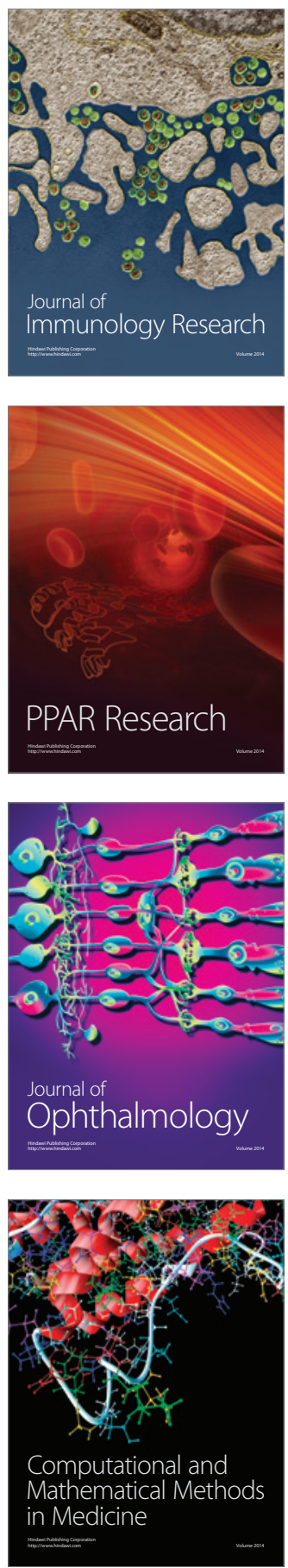

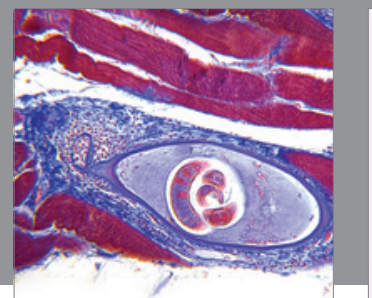

Gastroenterology

Research and Practice
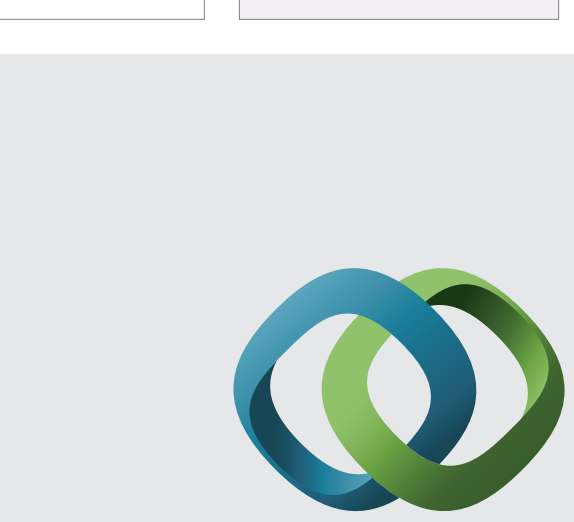

\section{Hindawi}

Submit your manuscripts at

http://www.hindawi.com
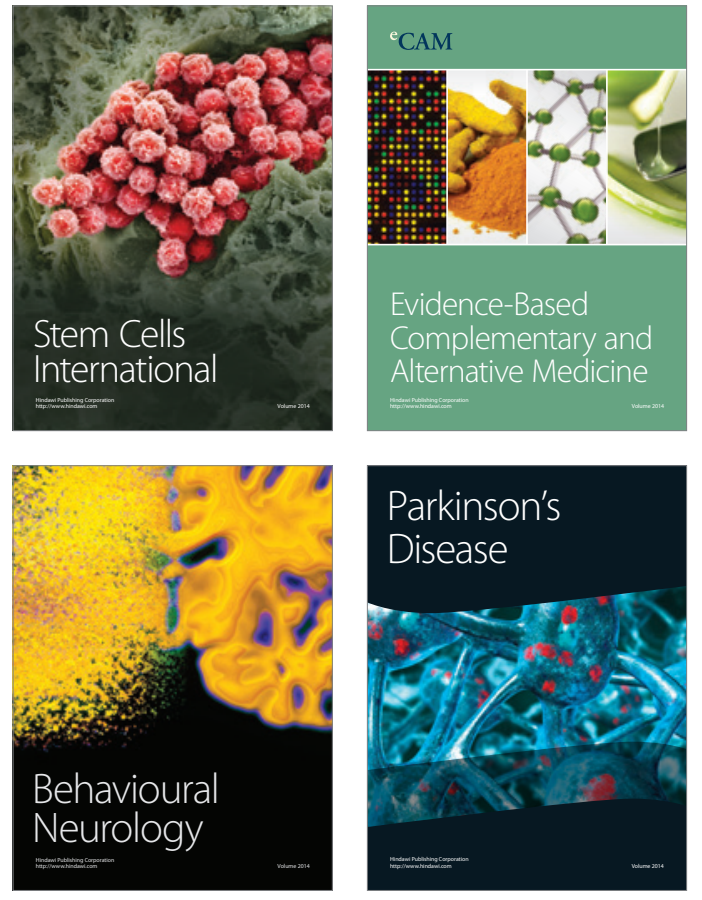
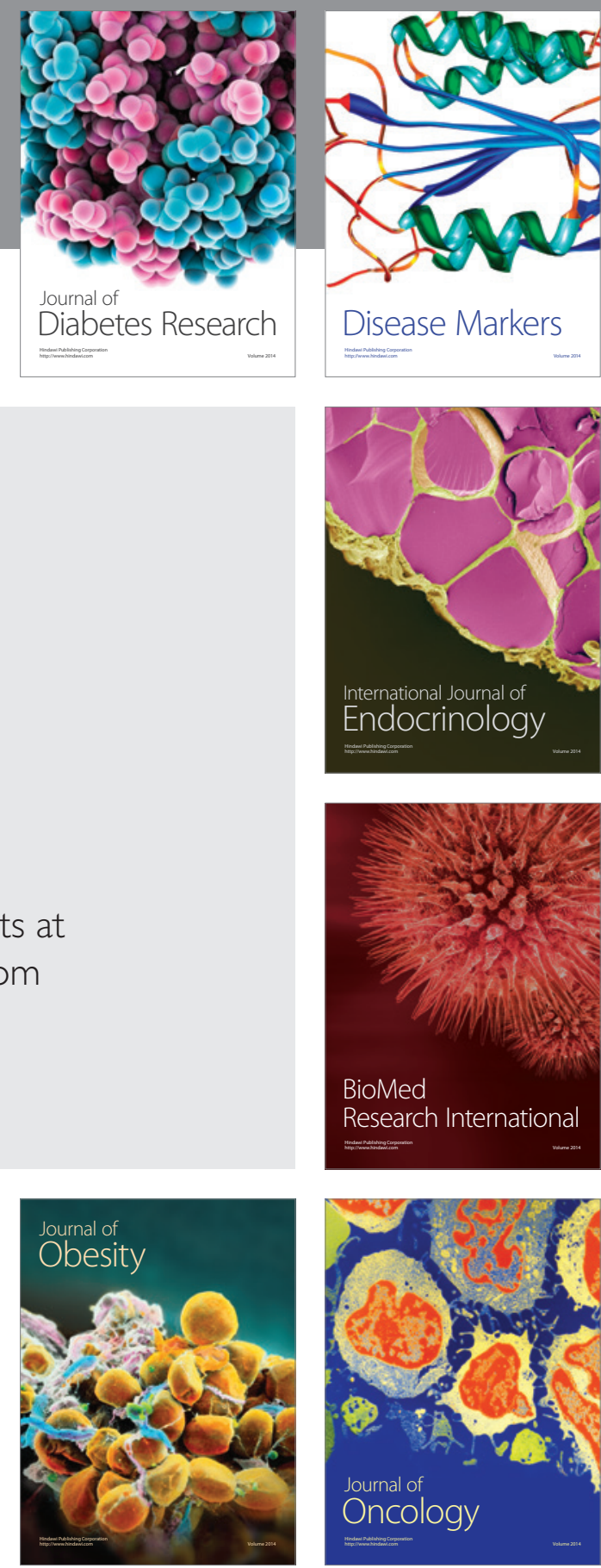

Disease Markers
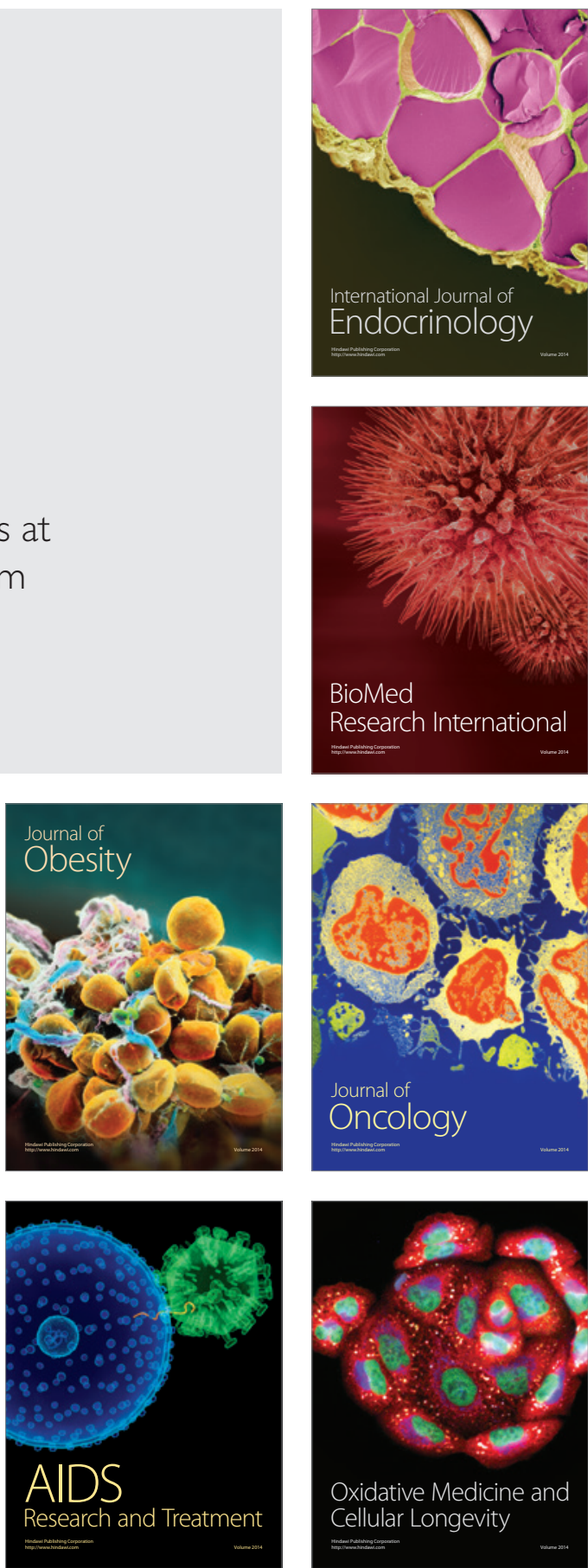